\title{
PENINGKATAN KUALITAS PELAYANAN MENGGUNAKAN METODE SERVQUAL DAN KANO
}

\author{
Wulan Purnamasari ${ }^{1}$, Rizki Bachtiar Yuliansyah ${ }^{2}$ \\ 1,2 Universitas Latif Maarif Hasyim \\ e-mail: wulan_purnamasari@dosen.umaha.ac.id ${ }^{1}$,rizki_bachtiar@dosen.umaha.ac.id ${ }^{2}$
}

\begin{abstract}
Abstrak
Penelitian ini secara garis besar bertujuan untuk meningkatkan kualitas pelayanan Digls Indonesia, dengan harapan keinginan dan kebutuhan konsumen dapat tercapai dan sesuai dengan ekspektasi mereka terhadap persepsi manajemen. Penggunaan metode Servqual dan Kano diharapkan nantinya dapat diidentifikasi adanya GAP antara keinginan dan kebutuhan pelanggan yang harus ditingkatkan dan respon teknis yang harus dilakukan manajemen, sehingga diharapkan kepuasan konsumen terhadap kualitas jasa Digls Indonesia meningkat sehingga perusahaan dapat berkembang dengan pesat. Penelitian ini dimulai dengan interview dan penyebaran kuesioner kepada 50 responden konsumen saat mendapatkan tanggapan tentang pelayanan Digls Indonesia yang digunakan untuk melakukan uji validitas dan reabilitas. Atribut pelayanan terdiri dari 30 item, memakai metode Servqual, diantaranya atas 5 dimensi, yaitu: reliability, tangibles, emphaty, responsiveness, serta assurance. Setelah dilakukan penyebaran kuesioner, tahapan selanjutnya adalah melakukan olah data dengan perhitungan GAP untuk mengetahui kepuasan konsumen terhadap atribut kualitas pelayanan Digls Indonesia. Selanjutnya diolah memakai metode Kano. Prioritas atribut yang perlu diperbaiki dan ditingkatkan oleh perusahaan Digls Indonesia agar sesuai dengan keinginan dan dibutuhkan pelanggan berdasarkan $\mathrm{VoC}$ (Voice of Customer) melalui metode Servqual dan Kano antara lain: Prioritas pertama pada dimensi tangible, Prioritas pertama pada dimensi reability, Prioritas pertama pada dimensi responsiveness, Prioritas utama pada dimensi assurance, dan Prioritas utama pada dimensi empathy. Usulan untuk meningkatkan pelayanan Digls Indonesia sesuai keinginan dan kebutuhan pelanggan berdasarkan VoC (Voice of Customer) dengan menggunakan metode Servqual dan Kano adalah perbaikan atau evaluasi SOP, peninjauan sarana dan prasarana (difokuskan pada fasilitas ruangan) serta pemberian pelatihan tambahan untuk menunjang kinerja SDM.
\end{abstract}

Kata kunci : Kualitas Pelayanan, Servqual, Kano

\begin{abstract}
This study aims to broadly improve the quality of Indonesian Digls services, in the hope that consumers' desires and needs can be achieved and in line with their expectations of management perceptions. The use of Servqual and Kano methods is expected to later identify the GAP between customer needs and needs that must be improved and the technical response that must be carried out by management, so that customer satisfaction is expected to increase the quality of Indonesian Digls services so that the company can grow rapidly. This research began with interviews and distributing questionnaires to 50 consumer respondents when getting responses about Indonesian Digls services used to test validity and reliability. Service attributes consist of 30 items using the Servqual method consisting of 5 dimensions, namely tangibles, reliability, empathy, assurance, and responsiveness. After distributing questionnaires, the next step is to do data processing with GAP calculations to determine customer satisfaction with the quality attributes of Indonesian Digls services. Then processed using Kano method. Priority attributes to be repaired and improved by Indonesian Digls companies to be in accordance with the wishes and needs of customers based on VoC (Voice of Customer) through Servqual and Kano methods among others : The first priority in the tangible dimension, The first priority in
\end{abstract}




\begin{abstract}
the reability, The first priority in the dimensions of responsiveness, and The main priority in the assurance dimension. While the main priority on empathy dimensions, is about providing information and instructions on how to operate the system clearly, the management should conduct an SOP evaluation, so that the operation of the system can run better. The proposal to improve Indonesian Digls services according to customer desires and needs based on VoC (Voice of Customer) using Servqual and Canoeing methods is the improvement or evaluation of SOPs, reviewing facilities and infrastructure (focused on room facilities) and providing additional training to support HR performance.
\end{abstract}

Keywords : Service Quality, Servqual, Kano

\section{PENDAHULUAN}

Digls Indonesia (Ina) adalah salah satu perusahaan jasa rancang bangun sebuah sistem informasi akuntansi. Digls Ina sebagai pengembang sistem, diantaranya: Project Based Aplication Development, Product Based Aplication Development, dan Upgrading System. Digls Ina bertempat di Jalan Palem Selatan II Blok MC No.165, Wadungasri-WaruSidoarjo. Dalam menjalankan kegiatan usahanya saat ini, Digls Indonesia kurang berkembang. Hal ini nampak dari banyaknya sistem yang utilitasnya masih rendah, disebabkan minimnya jumlah pengguna jasa Digls Indonesia. Salah satu faktor minimnya jumlah pengguna jasa Digls Indonesia adalah dari segi pelayanan yang kurang memuaskan. Pihak manajemen mengetahui penyebab ini dari keluhan dan testimoni dari pelanggan. Kurang puas terhadap pelayanan dirasakan oleh para konsumen Digls Ina, dengan demikian perlu diadakan penelitian tentang want's dan need's pelanggan. Hal ini perlu dilaksanakan guna memenuhi want's dan need's pelanggan serta meningkatkan kepuasan pelanggan. Terdapat methode's yang bisa dipakai guna menolong perusahaan tuk menaikkan kualitas pelayanan yang disesuaikan dengan keinginan dan kebutuhan pelanggan, diantaranya adalah memakai metode Servqual dan Kano. Servqual methode ialah metode yang dipakai guna mengukur kualitas atribut pelayanan dari sebuah dimensi, yang nantinya akan muncul gap yaitu (layanan yang diterima pelanggan- persepsi pelanggan) Pengukurannya metode ini dengan mengukur kualitas layanan dari atribut masing-masing dimensi, sehingga akan diperoleh nilai gap yang merupakan selisih antara persepsi pelanggan terhadap layanan yang diterima dengan harapan pelanggan terhadap layanan yang akan diterima. Kano Model pertama kali dipakai oleh seorang bernama: (Noriaki Kano, 1984). Model Kano memiliki tujuan guna mengkategorikan beberapa atribut suatu produk/ jasa.

Lewis dan Booms (dalam Tjiptono, 2012:157) menyebutkan kualitas pelayanan secara sederhana, yaitu ukuran seberapa bagus tingkat layanan yang diberikan mampu sesuai dengan ekspektasi pelanggan.

Service Quality (Servqual) ialah alat guna mengukur kualitas pelayanan yang mampu dipakai untuk menganalisis penyebab permasalahan layanan serta memahami bagaimana kualitas layanan mampu diperbaiki. Terdapat 5 kelompok karakteristik dimensi kualitas yang dipakai pelanggan untuk mengevaluasi jasa: (Tjiptono, 1995).

a. Bukti langsung (Tangibles), teridiri atas pegawai, fasilitas fisik, perlengkapan, dan sarana untuk pelanggan

b. Kehandalan (Reliability), merupakan kemampuan untuk menyediakan pelayanan yang dijanjikan secara cepat, akurat, dan memuaskan.

c. Daya tanggap (Responsiveness), merupakan keinginan para staf guna menolong pelanggan serta memberi layanan dengan tanggap.

d. Jaminan (Assurance), terdiri atas pengetahuan, kemampuan, kesopanan, dan karyawan dapat menjaga kepercayaan pelanggan dalam memberikan informasi.

e. Empati (Emphaty), terdiri atas kemudahan untuk komunikasi yang baik, menjalin hubungan, serta mengerti kebutuhan para pelanggan.

Metode Kano bertujuan untuk mengkategorikan atribut produk/ jasa berlandasakan seberapa baik produk/ jasa itu dapat memuaskan need's pelanggan.

Metode Kano dibedakan menjadi 3 kategori yang diingini pelanggan dan mampu 
mempengaruhi satisfaction pelanggan, yaitu: (Kano, 1984):

a. Must-be Requirements (MBR). Apabila kategori tersebut tidak dipenuhi, dengan demikian pelanggan akan merasa tidak puas. MBR adalah kriteria awal dari produk/ jasa. Pelanggan menganggap kategori ini wajib ada sehingga secara eksplisit tidak memuaskan mereka.

b. One-dimensional Requirements (ODR). Kepuasan pelanggan proporsional dengan kinerja atribut. Semakin tinggi kinerja atribut, semakin tinggi pula kepuasan pelanggan.

c. Attractive Requirements (AR). Kategori ini merupakan kriteria produk yang memiliki pengaruh paling besar pada kepuasan pelanggan jika diberikan.

\section{METODE}

Penelitian ini memakai Servqual dan Kano Method, karena metode tersebut cocok digunakan dalam peningkatan kualitas pelayanan. Dalam awal pelaksanaannya nanti, peneliti akan mengumpulkan data dari pihak perusahaan Digls Indonesia terkait dengan atribut pelayanan pada perusahaan tersebut, selain itu mengumpulkan informasi terkait dengan keinginan dan kebutuhan pelanggan terhadap pelayanan Digls Indonesia dari VoC (Voice of Costumer). Pengumpulan data atribut ini dilakukan, untuk mempermudah proses pengolahan data pada penelitian ini.

\section{HASIL DAN PEMBAHASAN}

Tabel 1. Atribut Pelayanan Jasa

\begin{tabular}{cll}
\hline Dimensi & Kode & \\
\hline & X.1 & Kebersihan ruangan \\
& X.2 & Kenyamanan ruang tunggu \\
& X.3 & Pengaturan pencahayaan \\
& X.4 & Pengaturan sirkulasi udara \\
Tangibles & X.5 & Pengaturan suhu ruangan \\
(Terwujud) & X.6 & Penataan tata letak ruangan \\
& X.7 & Papan informasi yang tersedia \\
& X.8 & Internet yang disediakan \\
& X.9 & Sarana pencarian informasi yang disediakan \\
& X.10 & Kerapian penampilan karyawan \\
& X.11 & Area lahan parkir \\
& X.12 & Kelengkapan sarana hiburan pada ruang tunggu (koran, majalah) \\
& X.13 & Ketelitian programmer dalam bekerja \\
& X.14 & Ketrampilan programmmer dalam bekerja \\
& X.15 & Kecepatan programmer dalam bekerja \\
& X.16 & Kedisiplinan programmmer dalam bekerja \\
& X.17 & Kemampuan programmer untuk pelayanan sistem informasi \\
& X.18 & Kemampuan programmer dalam menggunakan sistem informasi \\
& X.19 & Kelengkapan alat yang diberikan kepada pemakai sistem \\
Reliability & X.20 & Kelengkapan informasi yang diterima oleh pemakai sistem \\
(Kehandalan) & X.21 & Kecepatan akses mobile yang dioperasikan \\
& X.22 & Kemudahan sistem yang dioperasikan \\
& X.23 & Keamanan sistem yang dioperasikan \\
& X.24 & Kecepatan dalam memberikan pelayanan \\
& X.25 & Petugas layanan ready dan sigap untuk melayani pelanggan \\
& X.26 & Memberikan perbaikan yang cepat terhadap setiap keluhan \\
& X.27 & Petugan layanan memiliki pengetahuan dan kemampuan dalam \\
& X.28 & Keramahan petugas layanan \& sopan ketika memberi \\
& & \\
(Ketangivapananan &
\end{tabular}




\begin{tabular}{lll}
\hline \multirow{2}{*}{ Empathy (Empati) } & X.29 & Informasi \& petunjuk tata cara pengoperasian sistem yang \\
& X.30 & Keluhan \& saran direspon dengan baik \\
\hline
\end{tabular}

Tabel 2. Uji Validitas Tingkat Persepsi dan Ekspektasi Pelanggan

\begin{tabular}{cccccc}
\hline No & Kode Atribut & r Tabel & $\begin{array}{c}\text { Tingkat } \\
\text { Persepsi } \\
\text { r Hitung }\end{array}$ & $\begin{array}{c}\text { Tingkat } \\
\text { Ekspektasi } \\
\text { r Hitung }\end{array}$ & $\begin{array}{c}\text { Keterangan } \\
\text { Valid/ Tidak }\end{array}$ \\
\hline 1 & X.1 & 0.230 & 0.545 & 0.894 & Valid \\
2 & X.2 & 0.230 & 0.633 & 0.729 & Valid \\
3 & X.3 & 0.230 & 0.734 & 0.759 & Valid \\
4 & X.4 & 0.230 & 0.590 & 0.494 & Valid \\
5 & X.5 & 0.230 & 0.504 & 0.894 & Valid \\
6 & X.6 & 0.230 & 0.461 & 0.729 & Valid \\
7 & X.7 & 0.230 & 0.562 & 0.607 & Valid \\
8 & X.8 & 0.230 & 0.702 & 0.758 & Valid \\
9 & X.9 & 0.230 & 0.398 & 0.729 & Valid \\
10 & X.10 & 0.230 & 0.366 & 0.669 & Valid \\
11 & X.11 & 0.230 & 0.633 & 0.759 & Valid \\
12 & X.12 & 0.230 & 0.725 & 0.729 & Valid \\
13 & X.13 & 0.230 & 0.514 & 0.494 & Valid \\
14 & X.14 & 0.230 & 0.687 & 0.607 & Valid \\
15 & X.15 & 0.230 & 0.433 & 0.758 & Valid \\
16 & X.16 & 0.230 & 0.520 & 0.729 & Valid \\
17 & X.17 & 0.230 & 0.460 & 0.763 & Valid \\
18 & X.18 & 0.230 & 0.562 & 0.763 & Valid \\
19 & X.19 & 0.230 & 0.634 & 0.333 & Valid \\
20 & X.20 & 0.230 & 0.317 & 0.725 & Valid \\
21 & X.21 & 0.230 & 0.371 & 0.418 & Valid \\
22 & X.22 & 0.230 & 0.544 & 0.763 & Valid \\
23 & X.23 & 0.230 & 0.633 & 0.333 & Valid \\
24 & X.24 & 0.230 & 0.284 & 0.649 & Valid \\
25 & X.25 & 0.230 & 0.499 & 0.657 & Valid \\
26 & X.26 & 0.230 & 0.585 & 0.657 & Valid \\
27 & X.27 & 0.230 & 0.484 & 0.333 & Valid \\
28 & X.28 & 0.230 & 0.399 & 0.649 & Valid \\
29 & X.29 & 0.230 & 0.321 & 0.649 & Valid \\
30 & X.30 & 0.230 & 0.393 & 0.542 & \\
& & & & & \\
\hline
\end{tabular}

Dilihat dari table 2 diatas, maka dapat dilihat bahwasanya data persepsi dan ekspektasi pelanggan dari masing-masing atribut pada kuesioner memiliki nilai $r$ Hitung > nilai $r$ Tabel $=0,230$. Dengan demikian, seluruh atribut bersifat valid serta dapat dipakai tuk pengolahan data dan analisis berikutnya.

Tabel 3. Uji Reliabilitas Tingkat Persepsi

\begin{tabular}{ll}
\hline Cronbach's Alpha & Nof Items \\
\hline 0.904 & 30 \\
\hline
\end{tabular}

Dari table 3, terdapat hasil nilai $C A>0.6$ yaitu 0.904, dengan demikian dapat dinyatakan data keusioner mempunyai

Tabel 4. Uji Reliabilitas Tingkat Ekspektasi reliabilitas tinggi, sehingga dapat dijadikan acuan langkah analisis selanjutnya.
Cronbach's Alpha

0.957
$\mathrm{N}$ of Items

30 
Pada hasil pengujian reliabilitas dengan 30 responden, maka diperoleh nilai $C A>0.6$ yakni 0.957 , oleh karena itu dapat dinyatakan bahwa data hasil penyebaran kuesioner mempunyai reliabilitas tinggi sehingga mampu dipakai sebagai acuan analisis selanjutnya.

Tabel 5. Hasil Perhitungan GAP tiap Atribut

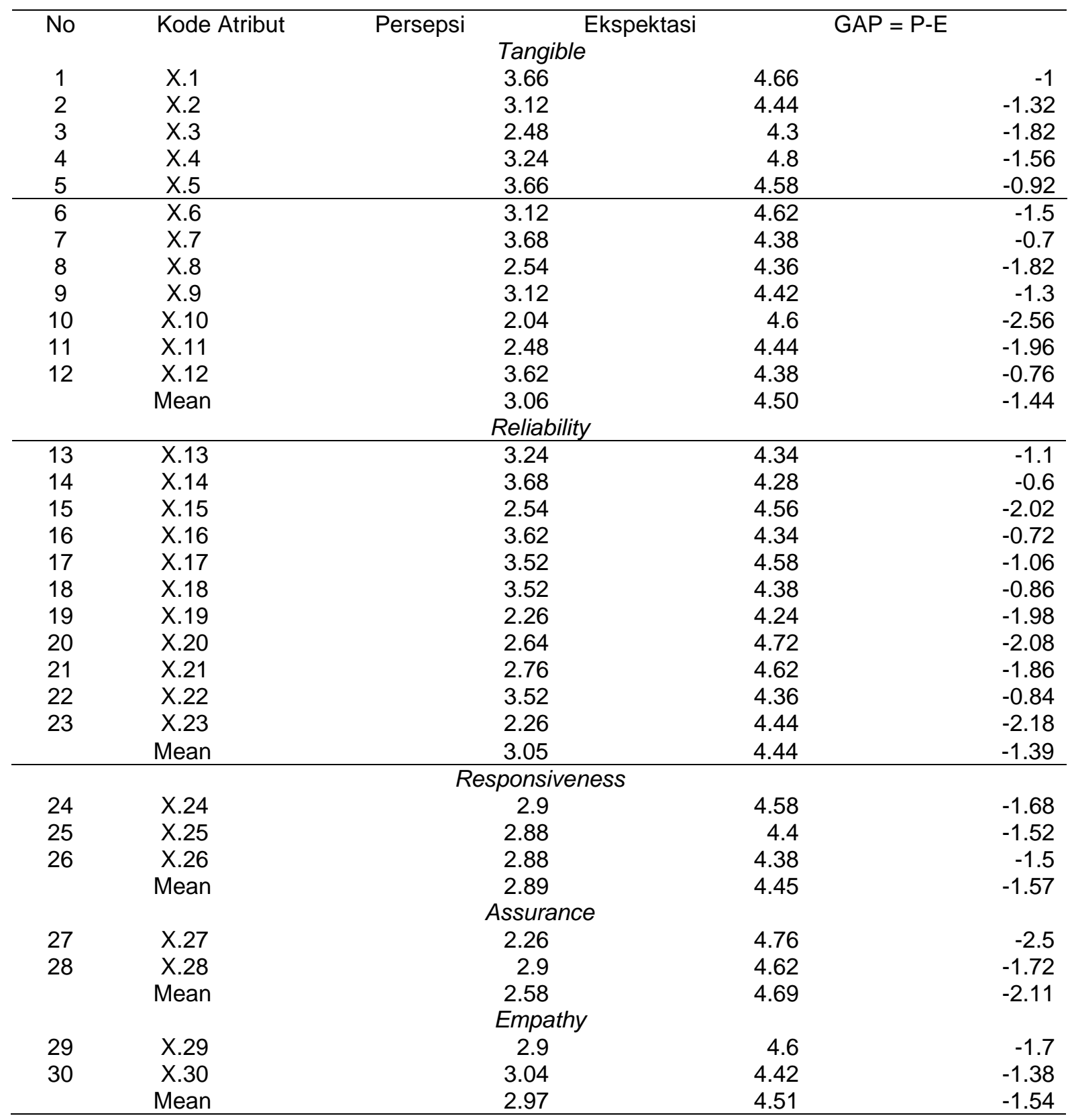

Berdasarkan hasil perhitungan GAP diatas, maka diketahui terdapat 30 atribut dengan kode atribut X.1 - X.30 yang memiliki nilai GAP negative, yang artinya semua atribut belum memenuhi ekspektasi konsumen. Berdasarkan seluruh perhitungan atribut yang terdapat pada GAP terdapat 12 atribut yang termasuk dalam dimensi tangibles (berwujud), 11 atribut dalam dimensi reliability (kehandalan), 3 atribut dalam dimensi responsiveness (ketanggapan), 2 atribut dalam dimensi assurance (jaminan kepastian), dan 2 atribut dalam dimensi empathy (empati). 
Tabel 6. Rancangan Usulan Peningkatan Kualitas Pelayanan Berdasarkan Prioritas

\begin{tabular}{|c|c|}
\hline Kode Atribut & Usulan Atribut \\
\hline \multicolumn{2}{|r|}{ Tangible } \\
\hline X.10 & Kerapian penampilan karyawan \\
\hline $\mathrm{X} .11$ & Area lahan parkir \\
\hline$X .3$ & Pengaturan pencahayaan \\
\hline $\mathrm{X} .8$ & Internet yang disediakan \\
\hline X.4 & Pengaturan sirkulasi udara \\
\hline X.6 & Penataan tata letak ruangan \\
\hline $\mathrm{X} .2$ & Kenyamanan ruang tunggu \\
\hline$X .9$ & Sarana pencarian informasi yang disediakan \\
\hline $\mathrm{X} .1$ & Kebersihan ruangan \\
\hline X.5 & Pengaturan suhu ruangan \\
\hline X.12 & Kelengkapan sarana hiburan pada ruang tunggu (koran, majalah) \\
\hline $\mathrm{X} .7$ & Papan informasi yang tersedia \\
\hline \multicolumn{2}{|r|}{ Reliability } \\
\hline $\mathrm{X} .23$ & Keamanan sistem yang dioperasikan \\
\hline X.20 & Kelengkapan informasi yang diterima oleh pemakai sistem \\
\hline X.15 & Kecepatan programmer dalam bekerja \\
\hline X.19 & Kelengkapan alat yang diberikan kepada pemakai sistem \\
\hline$X .21$ & Kecepatan akses mobile yang dioperasikan \\
\hline$X .13$ & Ketelitian programmer dalam bekerja \\
\hline$X .17$ & Kemampuan programmer untuk pelayanan sistem informasi \\
\hline$X .18$ & Kemampuan programmer dalam menggunakan sistem informasi \\
\hline X.22 & Kemudahan sistem yang dioperasikan \\
\hline X.16 & Kedisiplinan programmmer dalam bekerja \\
\hline$X .14$ & Ketrampilan programmmer dalam bekerja \\
\hline \multicolumn{2}{|r|}{ Responsiveness } \\
\hline$X .24$ & Kecepatan dalam memberikan pelayanan \\
\hline$X .25$ & Petugas layanan ready dan sigap untuk melayani pelanggan \\
\hline X.26 & Memberikan perbaikan yang cepat terhadap setiap keluhan pelanggan \\
\hline & $\begin{array}{c}\text { Assurance } \\
\text { Astikn }\end{array}$ \\
\hline $\mathrm{X} .27$ & $\begin{array}{l}\text { Petugas layanan memiliki pengetahuan dan kemampuan dalam } \\
\text { memberikan informasi }\end{array}$ \\
\hline X.28 & $\begin{array}{l}\text { Keramahan petugas layanan \& sopan ketika memberi } \\
\text { pelayanan }\end{array}$ \\
\hline \multicolumn{2}{|r|}{ Empathy } \\
\hline$X .29$ & $\begin{array}{l}\text { Informasi \& petunjuk tata cara pengoperasian sistem yang } \\
\text { Dijabarkan secara jelas }\end{array}$ \\
\hline X.30 & Keluhan \& saran direspon dengan baik \\
\hline
\end{tabular}

Dari masing-masing dimensi diambil average dari persepsi, ekspektasi dan nilai GAP. Hasilnya bisa dilihat di tabel 7 berikut ini: 
Tabel 7. Hasil Perhitungan GAP tiap Dimensi

\begin{tabular}{ccccc}
\hline No & Kode Atribut & Persepsi & Ekspektasi & GAP $=$ P-E \\
\hline 1 & Tangible & 3.06 & 4.50 & -1.44 \\
2 & Reliability & 3.05 & 4.44 & -1.39 \\
3 & Responsiveness & 2.89 & 4.45 & -1.57 \\
4 & Assurance & 2.58 & 4.69 & -2.11 \\
5 & Empathy & 2.97 & 4.51 & -1.54 \\
& Mean & 2.91 & 4.52 & -1.61 \\
\hline
\end{tabular}

Dari pengamatan tabel 7, nilai GAP terkecil pada dimensi reliability yaitu senilai 1.39. Sedangkan nilai GAP paling besar adalah terdapat pada dimensi assurance, dengan nilai -2.11. Sedangkan dilihat dari nilai rata-rata dimensi terdapat nilai GAP -1.61, yang artinya kelima dimensi tersebut masih belum memenuhi ekspektasi konsumen secara maksimal. Guna menganalisa kualitas pelayanan yang telah disediakan oleh manajemen DigisIndonesia kepada konsumen, maka dapat menggunakan rumus sebagai berikut:

$$
\text { Kualitas }(\mathrm{Q})=\text { Penilaian }(\mathrm{P}) / \text { Harapan }
$$

Jika, $Q \geq 1 \Rightarrow$ kualitas pelayanan dinyatakan baik. Berdasarkan penilaian dan harapan yang telah diperoleh untuk setiap dimensi, maka penggolongam kualitas masingmasing dimensi dapat ditinjau pada tabel 8 :

Tabel 8. Kualitas Pelayanan tiap Dimensi

\begin{tabular}{ccccc}
\hline No & Kode Atribut & Persepsi & Ekspektasi & Q=P/E \\
\hline 1 & Tangibles & 3.06 & 4.50 & 0.68 \\
2 & Reliability & 3.05 & 4.44 & 0.69 \\
3 & Responsiveness & 2.89 & 4.45 & 0.65 \\
4 & Assurance & 2.58 & 4.69 & 0.55 \\
5 & Empathy & 2.97 & 4.51 & 0.66 \\
& Mean & 2.91 & 4.52 & 0.64 \\
\hline
\end{tabular}

Hasil tabel 8 dinyatakan nilai kualitas dari per dimensi. Dimensi yang mendekati nilai $Q \geq 1$ adalah dimensi reliability dengan nilai 0.69. urutan yang ke-dua adalah pada dimensi tangibles yaitu senilai 0.68 , kemudian urutan ke-tiga adalah dimensi empathy dengan nilai 0.66 , urutan ke-empat adalah responsiveness dengan nilai 0.65 \& dimensi yang mempunyai kualitas pelayanan paling rendah ialah dimensi assurance, yaitu dengan nilai 0.55. Tabel 8 menjunjukkan nilai kualitas pelayanan dimensi servqual masih dibawah rata-rata nilai 1 , dengan nilai $Q$ senilai 0.64 . Dengan ini, maka dapat dinyatakan bahwa kualitas pelayanan secara keseluruhan yang disediakan oleh pihak manajemen Digls Ina belum memenuhi pengharapan konsumen.

Tabel 9. Total Kategori Kano setiap Atribut Layanan dari Keseluruhan Responden

\begin{tabular}{cccccccc}
\hline & \multicolumn{7}{c}{ Jumlah masing-masing kategori Kano } \\
\cline { 2 - 6 } Atribut Layanan & $\mathrm{Q}$ & $\mathrm{R}$ & $\mathrm{A}$ & $\mathrm{I}$ & $\mathrm{O}$ & $\mathrm{M}$ & Jumlah \\
X.1 & 0 & 0 & 2 & 6 & 35 & 7 & 50 \\
X.2 & 0 & 0 & 3 & 11 & 25 & 11 & 50 \\
X.3 & 0 & 0 & 4 & 11 & 26 & 9 & 50 \\
X.4 & 0 & 0 & 5 & 15 & 20 & 10 & 50 \\
X.5 & 0 & 0 & 8 & 11 & 15 & 16 & 50 \\
X.6 & 0 & 0 & 5 & 13 & 20 & 12 & 50 \\
X.7 & 2 & 0 & 8 & 13 & 20 & 7 & 50 \\
X.8 & 0 & 0 & 7 & 12 & 15 & 16 & 50 \\
X.9 & 2 & 0 & 8 & 10 & 18 & 12 & 50 \\
X.10 & 4 & 1 & 8 & 14 & 18 & 5 & 50 \\
X.11 & 1 & 1 & 5 & 16 & 20 & 7 & 50
\end{tabular}




\begin{tabular}{llll}
\hline X.12 & 1 & 1 & 5 \\
X.13 & 1 & 1 & 9 \\
X.14 & 1 & 1 & 8 \\
X.15 & 0 & 1 & 9 \\
X.16 & 1 & 0 & 8 \\
X.17 & 2 & 0 & 6 \\
X.18 & 2 & 0 & 5 \\
X.19 & 2 & 1 & 9 \\
X.20 & 2 & 0 & 7 \\
X.21 & 5 & 0 & 9 \\
X.22 & 2 & 2 & 8 \\
X.23 & 0 & 0 & 6 \\
X.24 & 0 & 0 & 4 \\
X.25 & 0 & 0 & 7 \\
X.26 & 0 & 0 & 5 \\
X.27 & 0 & 0 & 5 \\
X.28 & 0 & 0 & 5 \\
X.29 & 0 & 0 & 6 \\
X.30 & 4 & 0 & 3 \\
\hline
\end{tabular}

Keterangan:

$$
\begin{aligned}
\mathrm{Q} & =\text { questionsable } \\
& =\text { indifferent } \\
\mathrm{R} \quad & =\text { reverse } \\
& =\text { one dimensional } \\
\mathrm{A} \quad & =\text { attractive } \\
& =\text { must be }
\end{aligned}
$$

1. Menentukan kategori Kano tuk masingmasing atribut layanan.

Dalam menetukan kategori

Kano, peneliti memakai

Blauth Formula (Walden,

1993):

$$
\begin{aligned}
& \text { a. Apabila }(O+A+M)>(I+R+Q) \\
& \Rightarrow \text { grade diperoleh dari yang } \\
& \text { terbesar dari } O \rightarrow A \rightarrow M \\
& \text { b. Jika }(O+A+M)<(I+R+Q) \\
& \Rightarrow \text { grade diperoleh dari yang } \\
& \text { terbesar dari } I \rightarrow R \rightarrow Q
\end{aligned}
$$

Cara menentukan kategori Kano pada atribut layanan pertama: kebersihan lingkungan (X.1) berdasarkan Tabel 5.9 dengan nilai $(O+A+M)$ lebih besar dibandingkan dengan nilai $(I+R+Q$ ) yaitu (35 $+2+7)>(6+0+0)$. Dengan demikian grade yang dipilih adalah $\mathrm{O}$ karena nilainya terbesar dari $(35 ; 2 ; 7)$ dengan demikian atribut kebersihan lingkungan memeperoleh kategori One dimensional. Begitu juga dengan atribut layanan selanjutnya dengan cara yang sama.

Dimensi tangible: atribut layanan yang mampu menaikkan kepuasan konsumen adalah atribut: kebersihan ruangan, kenyamanan ruang tunggu, pengaturan

\begin{tabular}{ccc}
20 & 5 & 50 \\
21 & 5 & 50 \\
10 & 11 & 50 \\
17 & 13 & 50 \\
18 & 6 & 50 \\
16 & 11 & 50 \\
20 & 10 & 50 \\
18 & 10 & 50 \\
16 & 9 & 50 \\
20 & 6 & 50 \\
20 & 8 & 50 \\
18 & 8 & 50 \\
18 & 14 & 50 \\
16 & 14 & 50 \\
18 & 11 & 50 \\
20 & 10 & 50 \\
20 & 13 & 50 \\
20 & 9 & 50 \\
10 & 13 & 50 \\
\hline
\end{tabular}

pencahayaan, pengaturan sirkulasi udara, penataan tata letak ruangan, papan informasi yang tersedia, fasilitas internet yang tersedia dan sarana penelusuran informasi yang tersedia. Dimana atribut-atribut tersebut mendapat kategori one dimensional. Artinya, apabila atribut layanan tersebut tersedia dengan baik, maka hal ini mampu meningkatkan kepuasan konsumen, namun apabila kinerja atau persepsi atribut tersebut menurun, maka akan turun pula tingkat kepuasan konsumen terhadap pelayanan Digis Indonesia. Sedangkan kategori must be adalah atribut pengaturan suhu ruangan.

Untuk dimensi reliability: atribut layanan yang mampu menaikkan kepuasan konsumen dan akan mengakibatkan ketidakpuasan apabila tidak disediakan adalah atribut: kerapian penampilan karyawan, area lahan parker, kelengkapan sarana hiburan pada ruang tunggu (koran, majalah), ketelitian programmer saat bekerja, kecepatan programmer dalam bekerja, kedisiplinan programmmer dalam bekerja, kemampuan programmer untuk pelayanan sistem informasi, kemampuan programmer dalam menggunakan system, kelengkapan alat yang diberikan kepada pemakai system, kelengkapan informasi yang diterima oleh pemakai system, kecepatan akses mobile yang dioperasikan, kemudahan sistem yang dioperasikan dan keamanan sistem yang dioperasikan. Sedangkan yang disebut kategori must be adalah ketrampilan programmer dalam bekerja.

Sedangkan dimensi responsiveness: atribut layanan yang mampu menaikkan kepuasan konsumen \& akan mengakibatkan ketidakpuasan apabila tidak disediakan (one dimensional) adalah atribut: kecepatan dalam 
memberikan pelayanan, petugas layanan siap dan sigap dalam melayani pelanggan dan memberikan perbaikan yang cepat terhadap setiap keluhan pelanggan.

Pada dimensi assurance, atribut layanan yang mampu menaikkan kepuasan konsumen \& akan menyebabkan ketidakpuasan apabila tidak disediakan (one dimensional) adalah atribut: petugas layanan memiliki pengetahuan dan kemampuan dalam menyampaikan informasi dan keramahan petugas dan sopan dalam memberi layanan.

Sedangkan pada empathy dimension, atribut layanan yang dapat memberikan kepuasan konsumen \& mengakibatkan ketidakpuasan apabila tidak disediakan adalah atribut: informasi dan petunjuk tata cara pengoperasian sistem yang diberikan jelas. Untuk atribut layanan yang menjadi dasar dan sifatnya harus dipenuhi oleh manajemen, yang disebut kategori must be adalah keluhan dan saran direspon dengan baik.

Dilihat dari Preferensi Responden Pimpinan Pada dimensi tangible, atribut layanan yang mampu menaikkan kepuasan konsumen apabila tersedia \& mengakibatkan kepuasan menurun apabila tidak tersedia adalah atribut kebersihan ruangan, kenyamanan ruang tunggu, pengaturan pencahayaan, pengaturan sirkulasi udara, pengaturan suhu ruangan, penataan tata letak ruangan, papan informasi yang tersedia, sarana penelusuran informasi yang tersedia, kerapian penampilan karyawan dan area lahan parker. Menurut preferensi pimpinan, atribut layanan kelengkapan sarana hiburan di ruang tunggu (koran, tabloid) tidak berpengaruh pada kepuasan konsumen.

Di dimensi reliability, yang mampu menaikkan kepuasan konsumen \& akan menimbulkan ketidakpuasan apabila tidak disediakan adalah atribut: kecepatan programmer dalam bekerja, kedisiplinan programmmer dalam bekerja, kemampuan programmer untuk pelayanan sistem informasi, kelengkapan alat yang diberikan. kepada pemakai system, kecepatan akses mobile yang dioperasikan dan kemudahan sistem yang dioperasikan. Sedangkan atribut layanan-nya ialah ketelitian programmer dalam bekerja, ketrampilan programmmer dalam bekerja, kemampuan programmer dalam menggunakan system, kelengkapan informasi yang diterima oleh pemakai system dan keamanan sistem yang dioperasikan.

Pimpinan Digis Ina memiliki prefernsi bahwa di dimensi responsiveness, semua atribut layanan merupakan layanan yang harus dipenuhi karena dapat meningkatkan kepuasan konsumen.
Begitu pula pada dimensi assurance, pimpinan Digis Indonesia memiliki prefernsi bahwa seluruh atribut layanan harus dipenuhi, yaitu petugas layanan memiliki pengetahuan dan kemampuan dalam memberikan informasi dan keramahan petugas dan sopan memberi pelayanan.

Sedangkan pada dimensi empathy, atribut layanan yang mampu meningkatkan kepuasan konsumen dan akan menyebabkan ketidakpuasan adalah atribut: petunjuk tata cara serta informasi pengoperasian sistem yang disampaikan jelas, atribut layanan yang harus dipenuhi ialah keluhan dan saran direspon dengan baik

\section{PENUTUP}

Berdasarkan hasil analisis pada 30 atribut layanan yang memiliki pengaruh pada kepuasan konsumen. Terdapat 12 atribut yang termasuk pada dimensi tangible, 11 atribut dalam dimensi reliability, 3 atribut pada dimensi responsiveness, 2 atribut pada dimensi assurance dan 2 atribut pada dimensi empathy. Maka, dapat diperoleh kesimpulan sebagai berikut:

Atribut yang menjadi prioritas untuk diperbaiki dan ditingkatkan oleh perusahaan Digls Indonesia agar sesuai dengan keinginan dan dibutuhkan pelanggan berdasarkan VoC (Voice of Customer) melalui metode Servqual dan Kano adalah Prioritas pertama pada dimensi tangible adalah kerapian penampilan karyawan yang perlu ditingkatkan lagi, bila perlu diseragamkan (memakai dresscode). Prioritas pertama pada dimensi reability adalah keamanan sistem yang dioperasikan agar lebih ditingkatkan kembali dengan menjaga kerahasiaan database konsumen dan keamanan di dalam pengoperasian. Prioritas pertama pada dimensi responsiveness, adalah kecepatan petugas dalam memberikan pelayanan sebaiknya manajemen menyediakan training soft skill \& hard skill yang bisa menunjang kecepatan karyawan dalam memberikan pelayanan. Prioritas utama pada dimensi assurance, yaitu petugas memiliki pengetahuan dan kemampuan dalam memberikan informasi, dalam hal ini sebaiknya pihak manajemen memberikan pelatihan tambahan yang dapat menunjang pengetahuan para petugas layanan. Sedangkan prioritas utama pada dimensi empathy, adalah tentang pemberian informasi dan petunjuk tata cara pengoperasian sistem dengan jelas, sebaiknya manajemen melalukan evaluasi SOP, agar pengoperasian sistem dapat berjalan dengan baik. Yang perlu diusulkan untuk meningkatkan pelayanan di perusahaan Digls 
Ina sesuai dengan want's \& need's pelanggan sesuai VoC (Voice of Customer) dengan menggunakan metode Servqual dan Kano adalah perbaikan atau evaluasi SOP, peninjauan sarana dan prasarana (difokuskan pada fasilitas ruangan) serta pemberian pelatihan tambahan untuk menunjang kinerja SDM.

\section{DAFTAR PUSTAKA}

Al Abrar, Andi Hakim. (2013). Peningkatan Kualitas Pelayanan Melalui Integrasi Metode Servqual dan Metode Kano ke Dalam Quality Function Deployment. Yogyakarta: Universitas Islam Negeri Sunan Kalijaga.

Bachtiar, Arfan, dkk. (2010). Analisis Kualitas Pelayanan Yang Berpengaruh Terhadap Kepuasan Pelanggan Menggunakan Metode Servqual Dan Model Kano (Studi Kasus: PT. PLN UPJ Semarang Selatan). UNDIP. Jurnal Vol V, No 2, Mei 2010.

Dwi, Yunita. (2013). Analisis Kualitas Pelayanan Perpustakaan dengan Metode Servqual dan Kano.

Yogyakarta: Universitas Islam Negeri Sunan Kalijaga.

Irianty. (2014). Pemetaan Preferensi Pelanggan Supermarket di Surabaya dan Sekitarnya dengan Metode Kano Berdasarkan Dimensi Servqual. Surabaya : Universitas Kristen Petra.

Kano, N., K. Seraku, F. Takahashi, S. Tsuji. (1984). "Attractive Quality and Must-be Quality", The Journal of the Japanese Society for Quality Control, Vol. 14, No. 2, Pp. 39-48.

Kriswanto, Widiawan. (2004). Pemetaan Preferensi Konsumen Supermarket dengan Metode Kano Berdasarkan Dimensi Servqual. Universitas Kristen Petra: Jurnal Teknik Industri Vol. 6, No. 1, Juni 2004: 37 - 46.

Nofirza dan Kus Indrayani. (2011). Aplikasi Metode Kano Dalam Analisis Indikator Kualitas Pelayanan di Rumah Sakit Arifin Ahmad Pekanbaru. UIN SUSKA Riau: Jurnal Sains, Teknologi dan Industri. Vol. 9 No. 1, 2011.

Parwati, Niken dan Ricky Martinus. (2011). Usulan Peningkatan Kualitas Pelayanan PT. X dengan Model Servqual dan Kano.
Universitas Al Azhar Jakarta: Jurnal Inovisi. Vol. 7 No. 1, April 2011.

Soedjono, Monika. (2012). Analisis dan Usulan Perbaikan Kualitas Layanan Menggunakan Integrasi Metode Servqual, Model Kano dan QFD di Warung Ipang Cabang Mayjend Sungkono Surabaya. UNESA: Jurnal Teknik Industri. Vol 1 No. 1,2012 